\title{
A new seismic survey technology using underwater speaker detected a low-velocity zone near the seafloor: an implication of methane gas accumulation in Tokyo Bay
}

\author{
Tetsuro Tsuru ${ }^{*^{*} \mathbb{D}}$, Kazuo Amakasu', Jin-Oh Park², Junichi Sakakibara ${ }^{3}$ and Mamoru Takanashi
}

\begin{abstract}
Owing to the strict restrictions on the use of air guns in marine seismic surveys due to concerns about their potential impact on the marine ecosystem, there have been several cases where seismic surveys were not permitted. This tendency has been particularly significant in coastal waters where fishing activity is flourishing, which creates blank zones in seismic surveys. The authors, therefore, adopted underwater speakers as environment-friendly seismic sources that can be used under such restrictions. In December 2017, the applicability of underwater speakers as a seismic source was tested in a seismic reflection experiment in the northern part of Tokyo Bay. As a result, shallow subsurface structures were successfully imaged, and a low-velocity zone was detected 7-8 $\mathrm{m}$ below the seafloor. In this paper, the concept of environment-friendly seismic survey using underwater speakers is reported. In addition, the potential presence of a methane gas layer that was detected in the low-velocity zone is discussed. If the methane gas is widely distributed near the seafloor in the northern part of Tokyo Bay, a large amount of gas might be released into the water and then into the air when, for example, a large-scale earthquake occurs directly underneath the Tokyo Bay area. Given the high flammability of methane, the features and volume of its distribution must be precisely investigated from the perspective of earthquake occurrences in the metropolitan area.
\end{abstract}

Keywords: Seismic survey, Underwater speaker, Environment-friendly, Non-explosive source, Methane gas, Near seafloor, Tokyo Bay

\section{Introduction}

Seismic reflection technology has developed as a method to image subsurface structures, especially in the oil and gas exploration industry. It is possible to identify sedimentary structures from the reflection configuration and faults by offsetting the reflections on the seismic reflection profiles (e.g., Tsuru et al. 2018). At present, the use of seismic reflection technology has expanded into other areas, including crustal studies in seismogenic zones for earthquake disaster prevention (e.g., Park et al. 2002;

\footnotetext{
${ }^{*}$ Correspondence: ttsuru0@kaiyodai.ac.jp

1 Academic Assembly, Tokyo University of Marine Science

and Technology, 4-5-7 Konan, Minato-ku, Tokyo 108-8477, Japan

Full list of author information is available at the end of the article
}

Tsuru et al. 2002) and carbon capture and storage (Tsuji et al. 2014).

Recently, the use of explosive type of energy sources such as air guns was restricted because of its potential impacts on marine mammal and fish species (IOGP 2017). This restriction is particularly severe in coastal waters such as Tokyo Bay, where detailed geological structures are still unknown because of a lack of seismic data. Therefore, we are developing an environment-friendly seismic survey system that uses underwater speakers (UWSs) as a non-explosive type of energy source. Explosive sources instantly generate impulsive waves with high sound pressure, whereas non-explosive sources generate non-impulsive waves with low sound pressure over a certain period of time. Using an energy source with low sound pressure, it is possible to conduct 
seismic surveys with a relatively low environmental impact on marine ecosystems.

Seismic surveys in Tokyo Bay are also important for modeling the structures in the surrounding Kanto basin (e.g., Koketsu et al. 2009). Recent seismological studies revealed that shallow geological structures control long-period ground motions (e.g., Takemura et al. 2015), which may cause severe damages to large-scale manmade structures such as high-rise buildings, oil tanks and suspension bridges (Koketsu and Miyake 2008).

In December 2017, a seismic reflection experiment was conducted to evaluate the exploration ability of UWSs as a seismic energy source in the northern part of Tokyo Bay. In this paper, we report the results of the experiment and show the applicability of UWS technology as a next generation seismic source that is environment friendly. In addition, we discuss the presence of a methane gas layer, which was detected near the seafloor, from the perspective of earthquake disaster prevention in metropolitan areas.

\section{Method}

Compared to explosive sources that instantly shoot an impulsive wave with a considerably higher level of sound pressure (Fig. 1a, d), non-explosive sources generate non-impulsive waves with relatively smaller level of sound pressure for a certain period of time (Fig. 1b, d). By taking the cross-correlation between the nonimpulsive wave and an observed record that includes a series of reflections originating from the non-impulsive wave source, the observed record is converted into a series of impulsive reflections (Fig. 1c). In this survey, it is possible to obtain high-resolution subsurface structural images using the non-impulsive source, which are as good as those obtained using an explosive source. This data processing method is the same as that used in onshore vibroseis surveys (Yilmaz and Doherty 1987).

The sound pressure levels (SPLs) of both explosive and non-explosive sources are compared in Fig. 1d. The former has an SPL of more than $160 \mathrm{~dB}$ in the frequency range below $400 \mathrm{~Hz}$, which is greater than the pressure level that threatens aquatic mammals and fish (Hatakeyama et al. 1997). Conversely, the latter has an SPL of about $130 \mathrm{~dB}$ in the frequency range of 100 $1000 \mathrm{~Hz}$, which is significantly less threatening. This shows that non-explosive sources have less impact on marine ecosystems.

Here, we consider the effect of increasing the signal-to-noise $(\mathrm{S} / \mathrm{N})$ ratio by cross-correlation processing. Based on a numerical experiment in which it is assumed that the UWS oscillates the source wavelet shown in Fig. $1 \mathrm{~b}$ for $10 \mathrm{~s}$ and the $\mathrm{S} / \mathrm{N}$ ratio of observed wave is 1 , the $\mathrm{S} / \mathrm{N}$ ratio increases by about 20 times with cross-correlation processing. Namely, the increase in the $\mathrm{S} / \mathrm{N}$ ratio due to cross-correlation processing of UWS source wave used in this study is about $26 \mathrm{~dB}$. Since the increase in the $\mathrm{S} / \mathrm{N}$ ratio is equivalent to the effect of increasing the SPL of a source wave, the SPL of the UWS used in this study becomes larger by about $26 \mathrm{~dB}$ after cross-correlation processing. As a result, the SPL of the UWSs becomes larger than that of an air gun in the frequency range greater than about
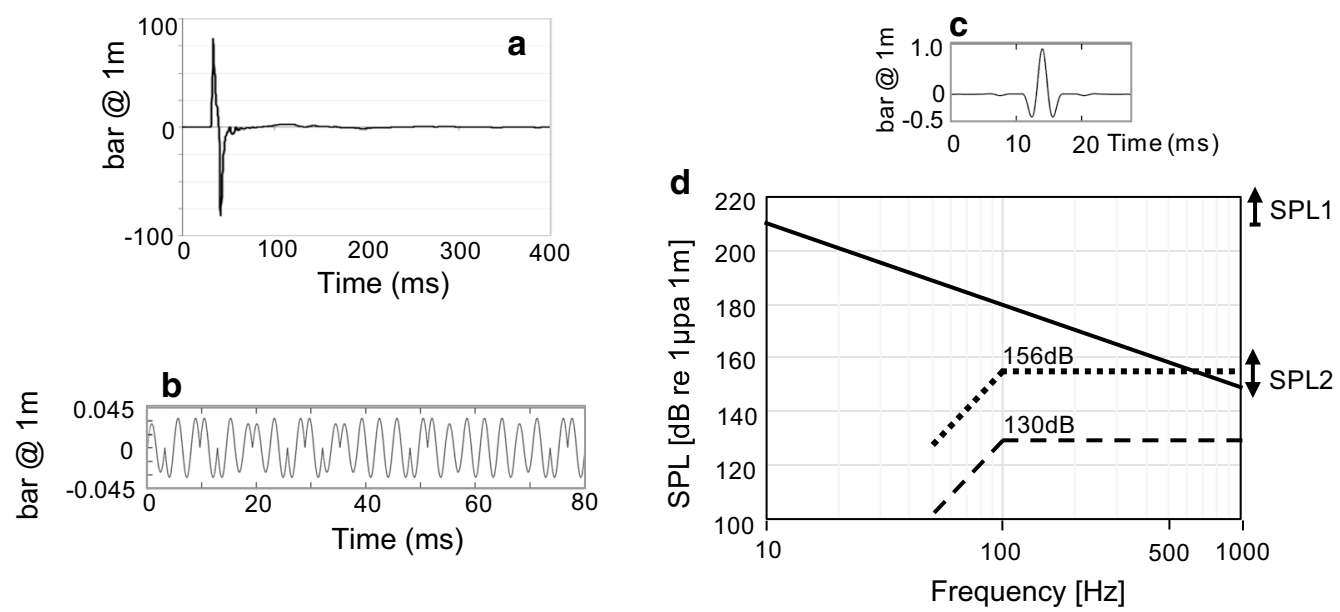

Fig. 1 a An example of source wavelet of the air gun (IAGC 2002), which instantly shoots an impulsive wave. $\mathbf{b}$ An example of source wavelet of the UWS, which generates a non-impulsive wave for a certain period. c An example of cross-correlated wavelet between the UWS source wave and an observed wave. $\mathbf{d}$ The sound pressure levels (SPLs) of the air gun and the UWS. The solid line shows the SPL of the air gun (IAGC 2002). The broken line and dotted line represent the SPLS of the UWS (provided by UETAX Corporation) before and after cross-correlation processing, respectively. SPL1 and SPL2 are the SPLs that harm fish and pose a threat to fish, respectively (Hatakeyama et al. 1997) 
$650 \mathrm{~Hz}$. Thus, UWSs can provide high-resolution images for shallow structures.

\section{Experiment}

In December 2017, a seismic experiment using a UWS was conducted by T/V Hiyodori of the Tokyo University of Marine Science and Technology in the northern part of Tokyo Bay. The seismic line was set in the WNW-ESE direction at a water depth of 8-9 m, as shown in Fig. 2a. The northern part of the Tokyo Bay is known to be a sea area with active fishery and busy marine traffic (e.g., Inaishi et al. 2006; Japan Coast Guard 2012). Although a few seismic surveys have been conducted in this region for the purpose of research on earthquake disaster prevention (e.g., Iwabuchi et al. 1995; Sato et al. 2005), no seismic survey has been performed since 2004 .

During the experiment, seismic reflection data for a length of around $540 \mathrm{~m}$ were collected using a UWS. The shooting was conducted with a shot point interval of $10 \mathrm{~s}$, which corresponds to a shot point spacing of $10 \mathrm{~m}$ with a boat speed of 2 knots, which was the standard used in the present experiment. The recording was done using an eight-channel streamer cable with a group spacing of $3.125 \mathrm{~m}$. The sampling rate and record length (after cross-correlation) were $1 \mathrm{~ms}$ and $1 \mathrm{~s}$, respectively. For the source waveform, a pseudorandom wave generated using the Mersenne Twister method (Matsumoto and Nishimura 1998), which is one of the random number generator algorithms used in MATLAB, was used.

\section{Results and discussion}

Figure $2 \mathrm{~b}$ shows the seismic profile obtained from the experiment. Continuous reflections from the seafloor are visible at about $11 \mathrm{~ms}$ in two-way travel time. Beneath the seafloor reflections, several continuous reflections can be observed clearly, including a continuous reflection with a significantly high amplitude (Ref. A) and a somewhat continuous reflection with a low amplitude (Ref. B). Beneath those reflections, a continuous reflection with somewhat low amplitude (Ref. C) is visible.

First, we discuss the depth of penetration in the present survey using the UWS. The deepest signal reflection that is reflected from a subsurface geological formation can be identified (Ref. C) based on its continuity over the entire seismic profile. Since no continuous reflections are reliably recognized below Ref. $\mathrm{C}$, the penetration depth of the UWS survey system used in this study area was at least $50 \mathrm{~ms}$, which corresponds to $37.5 \mathrm{~m}$ when we assume that the average velocity is $1500 \mathrm{~m} / \mathrm{s}$.

Next, Ref. A is considered. As shown in Fig. 2b, Ref. A has conspicuous characteristics: significantly high amplitude and reverse polarity. These characteristics are supported by the results of the velocity analysis. As shown in Fig. 3, the three velocity models were tested: one-layer velocity model with $1500 \mathrm{~m} / \mathrm{s}$ velocity (Fig. 3a), two-layer model with velocities of $1500 \mathrm{~m} / \mathrm{s}$ and $1100 \mathrm{~m} / \mathrm{s}$ (Fig. 3b) and two-layer model with velocities of $1500 \mathrm{~m} / \mathrm{s}$ and $1600 \mathrm{~m} / \mathrm{s}$ (Fig. 3c). Based on the flatness of the reflections of the model shown in Fig. 3b, the existence of a low-velocity zone immediately below Ref. A can be confirmed. According to the theory of reflection coefficient (e.g., Sheriff and Geldart 1995), the large velocity gap at

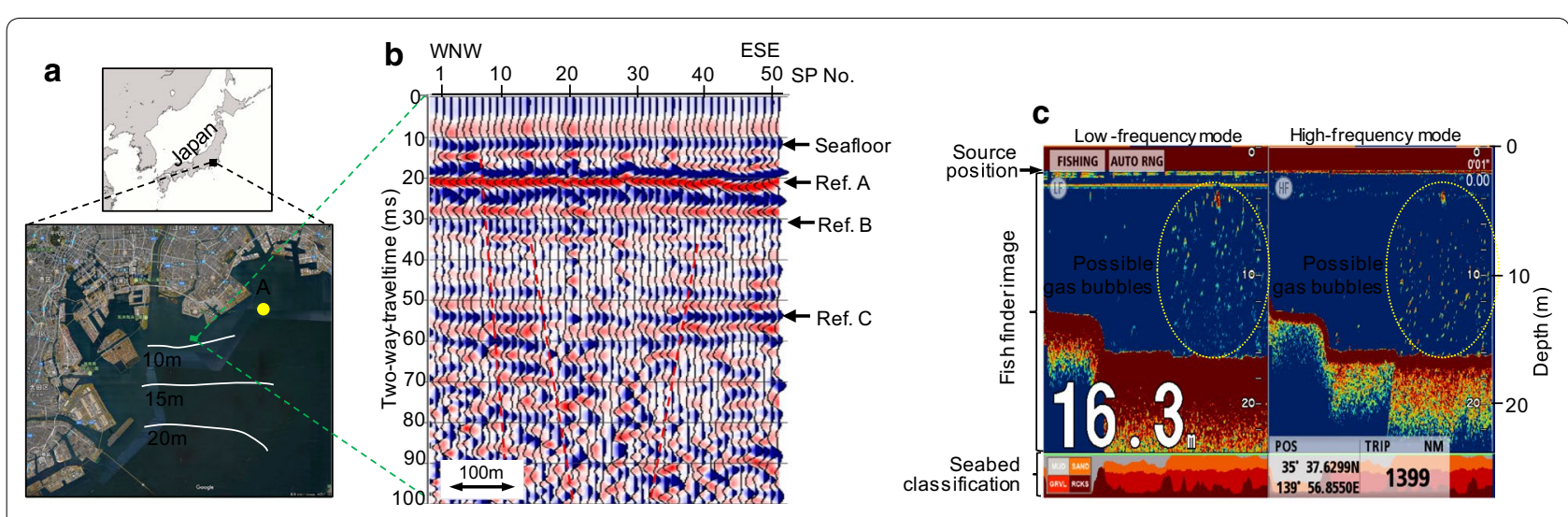

Fig. 2 a Location map of the seismic experiment conducted in December 2017. The survey area is located at the northernmost part of Tokyo Bay. The white contour lines and two-digit numbers represent water depths. b Resulting seismic reflection profile, which was stacked by a constant velocity of $1500 \mathrm{~m} / \mathrm{s}$. Blue color indicates positive amplitude and red color indicates negative amplitude. c Fish finder images that suggest the presence of a gas foaming phenomenon, observed at location A (see a) by TN Hiyodori in the spring of 2017 . The colors in the fish finder images represent the reflection strength of either the fish or seabed: Warmer colors indicate higher strength and colder colors indicate lower strength. The colors in the seabed classification section represent lithology: Gray, orange, red and brown colors show mud, sand, gravel and rock facies, respectively 


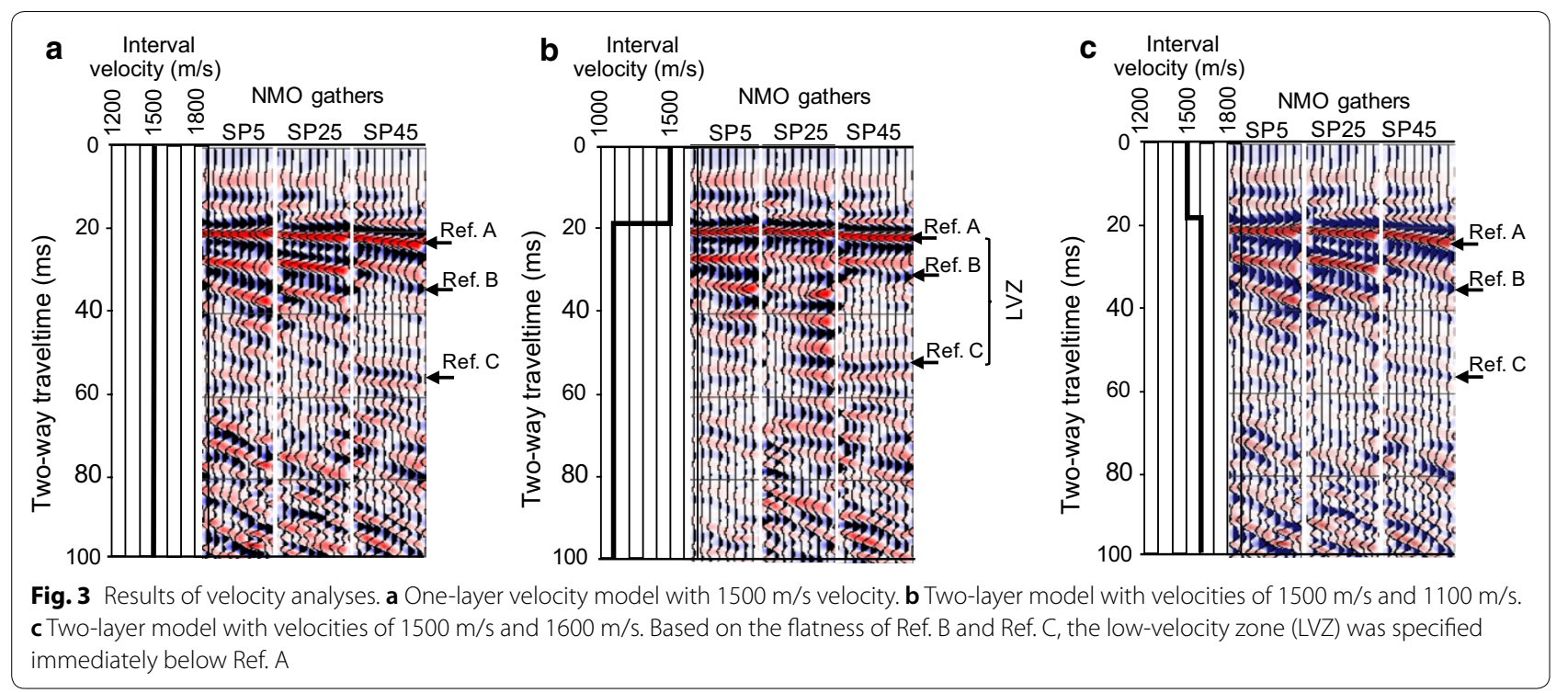

the interface in this model well explains the significantly high amplitude of Ref. A, whereas the low velocity that is detected is consistent with its reverse polarity. Since the estimated velocity of the low-velocity zone is $1100 \mathrm{~m} / \mathrm{s}$, which is considerably less than $1500 \mathrm{~m} / \mathrm{s}$ (the water velocity), the zone must contain gas. In the oil and gas exploration industry, these conspicuous characteristics are well known as the Bright Spot phenomenon and are typically used to identify gas reservoirs (Sheriff and Geldart 1995).

However, the depth of the detected gas layer is about 7-8 $\mathrm{m}$ below the seafloor when the velocity above Ref. A is $1500 \mathrm{~m} / \mathrm{s}$, which indicates that there is only a 7-8-m-thick sediment acting as a vertical seal over the gas. Compared with the general thickness of vertical seals over hydrocarbon reservoirs, which is larger than several $100 \mathrm{~m}$, the thickness of 7-8 $\mathrm{m}$ for the seal would be unreliable to prevent the release of hydrocarbons for millions of years or more. Although it is difficult to clarify why the gas has potentially accumulated below such a thin seal layer, the gas may dynamically or temporally accumulate for a certain period of time due to the balance between supply from a deeper layer and upward leakage.

The evidence of methane gas in the northern part of Tokyo Bay has been reported in previous studies (Furota 1987; Iwabuchi et al. 1995). However, such an extremely shallow methane layer has never been observed. If the low-velocity zone contains methane, the present study suggests that the gas is distributed near the seafloor in the northern part of Tokyo Bay. In addition, fish finder images suggest the presence of a gas foaming phenomenon on the dredged seafloor near the study area (provided by Mr. Takeuchi K., the Captain of T/V Hiyodori), as shown in Fig. 2c. Interestingly, this phenomenon can be seen only on the most deeply dredged seafloor, where there are only little mud deposits. Given that vertical sealability is proportional to the thickness of the seal in an environment with uniform seal material (mud deposits in the study area), this possible gas foaming phenomenon "visible on the seafloor with the thinnest seal" may be consistent with our interpretation of "dynamic or temporal accumulation of gas under the balance between supply from a deeper layer and upward leakage".

Here, we consider where the gas comes from. As for the methane gas foaming from the seafloor, it may be thought that the methane is produced by biological decomposition from the sludge deposited over the seafloor. However, according to a previous study (Takii et al. 2001) in the northern part of Tokyo Bay, the methane produced by biological decomposition from the sludge was observed only at depressed topographies such as dredged shipping lanes and sand mining sites, but not on undredged natural seafloor. The low-velocity zone was discovered in the natural seafloor (Fig. 2a, b); therefore, the biological decomposition from the sludge is not a likely candidate for the cause of methane accumulation.

As another candidate, the natural gas dissolved in water (NGDW) may be related to the methane accumulation causing the low-velocity zone. It is well known that NGDW is distributed widely under the metropolitan area in Japan, which includes the northern part of Tokyo Bay. A portion of the gas leaks out to the surface via faults and is utilized for household purposes in areas near Tokyo Bay (Sawaki and Kaneko 2010). However, the gas has caused some explosion accidents during civil engineering works in and around Tokyo (MLIT 2007). Considering 
that some faults near the seafloor have been discovered in previous seismic reflection studies (e.g., Kato 1984), there is a possibility that the low-velocity zone contains methane gas that migrated from deeper regions via such faults. If so, a large volume of methane could be distributed widely over the northern part of Tokyo Bay.

The northern part of Tokyo Bay has a potential risk of near-field earthquakes such as the 1855 Ansei Edo earthquake (e.g., Usami 1996; Bakun 2005). If an earthquake occurs, the faults would be activated, and a significant volume of methane gas might be released into the air. Methane not only causes a significant greenhouse effect, but is also highly flammable; therefore, it is important to identify the features and volume of its distribution. Hence, further seismic surveys are strongly required in the northern part of Tokyo Bay, even though the area appears as a blank zone in seismic surveys because of the active fishery and busy marine traffic.

\section{Conclusions}

The applicability of UWSs as an environment-friendly seismic source was tested in the northern part of Tokyo Bay. As a result, the shallow geological structures were clearly imaged down to at least $37.5 \mathrm{~m}$ below the seafloor. In addition, a low-velocity zone, suggesting methane gas accumulation, was discovered about 7-8 $\mathrm{m}$ below the seafloor. Considering both the high level of greenhouse effects and flammability of methane, the features and volume of its accumulation must be investigated from the perspective of environmental conservation and earthquake disaster prevention.

\section{Additional file}

Additional file 1. Seismic reflection data shown in Fig. $2 \mathrm{~b}$ are available as the additional file with CSV format.

\section{Authors' contributions}

TT is responsible for the entire manuscript. KA contributed to the data acquisition in the seismic experiment. J-OP contributed to the design of the study and the interpretation of seismic data. JS contributed to the design of the data acquisition system. MT contributed to the data analysis for source wavelet optimization. All authors read and approved the final manuscript.

\section{Author details}

${ }^{1}$ Academic Assembly, Tokyo University of Marine Science and Technology, 4-5-7 Konan, Minato-ku, Tokyo 108-8477, Japan. ${ }^{2}$ Atmosphere and Ocean Research Institute, The University of Tokyo, 5-1-5, Kashiwanoha, Kashiwa-shi, Chiba 277-8564, Japan. ${ }^{3}$ JFE Civil Engineering and Construction, 2-17-4 Kuramae, Taito-ku, Tokyo 111-0051, Japan. ${ }^{4}$ Japan Oil, Gas and Metals National Corporation, 2-10-1 Toranomon, Minato-ku, Tokyo 105-0001, Japan.

\section{Acknowledgements}

We would like to express our appreciation to the Captain and First Engineer of TN Hiyodori for their efforts in acquiring good-quality seismic data. This study was supported by a Grant-in-Aid for Scientific Research from the Japan Society for the Promotion of Science (No. JP15H05717 and No. JP18H03732).
The authors would also like to thank Dr. Seishiro Furuyama, Dr. Kosaku Arai and Dr. Takahiko Inoue of the National Institute of Advanced Industrial Science and Technology for their cooperation in the data acquisition. The comments of two anonymous reviewers have greatly improved the earlier version of this manuscript.

\section{Competing interests}

The authors declare that they have no competing interests.

\section{Availability of data and materials}

Seismic reflection data after stacking were provided as a Additional file 1 with csv format.

\section{Funding}

This study was supported by Grant-in-Aid for Scientific Research from the Japan Society for the Promotion of Science No. JP15H05717 in data collection and No. JP18H03732 in data analysis.

\section{Publisher's Note}

Springer Nature remains neutral with regard to jurisdictional claims in published maps and institutional affiliations.

Received: 20 November 2018 Accepted: 4 March 2019

Published online: 21 March 2019

\section{References}

Bakun WH (2005) Magnitude and location of historical earthquakes in Japan and implications for the 1855 Ansei Edo earthquake. J Geophys Res Solid Earth. https://doi.org/10.1029/2004JB003329

Furota T (1987) Blue coloured anoxic up-welling in Tokyo Bay. J Water Pollut 10:470-474 (in Japanese)

Hatakeyama Y, Inoue Y, Takei T, Sakaguchi S, Fujii K, Ikeda A, Kitagawa T (1997) Effects of underwater sounds on fish, fisheries research monograph. Jpn Fish Resour Conserv Assoc 47:73-109

IAGC (2002) Airgun arrays and marine mammals. International Association of Geophysical Contructors, USA

Inaishi M, Kondo M, Kawaduchi A (2006) Marine traffic simulation using ship agent clusters: northbound traffic in Tokyo Bay. J Jpn Inst Navig 115:11-16 (in Japanese)

IOGP Report 576 (2017) Seismic surveys and marine mammals-joint IOGP/ IAGC position paper. International Association of Oil and Gas Producers and International Association of Geophysical Contractors

Iwabuchi Y, Kato S, Kishimoto H, Kusunoki K, Watanabe K (1995) Three dimensional multi-channel seismic survey of the northern Tokyo Bay. Rep Hydrogr Res 31:1-15 (in Japanese)

Japan Coast Guard (2012) For the safe navigation in Japanese coastal waters. https://www.kaiho.mlit.go.jp/syoukai/soshiki/toudai/navigation-safet y/japan\%20coastal\%20navigation\%20safety\%20reference/english.pdf.. Accessed 1 Nov 2018

Kato S (1984) Submarine geological structure in Tokyo Bay. J Geography 93(3):119-132

Koketsu K, Miyake H (2008) A seismological overview of long-period ground motion. J Seismol 12:133-143. https://doi.org/10.1007/s1095 0-007-9080-0

Koketsu K, Miyake H, Afnimar, Tanaka Y (2009) A proposal for a standard procedure of modeling 3-D velocity structures and its application to Tokyo metropolitan area, Japan. Tectonophysics 472:290-300. https://doi. org/10.1016/j.tecto.2008.05.037

Matsumoto M, Nishimura T (1998) Mersenne twister: a 623-dimensionally equidistributed uniform pseudo-random number generator. ACM Trans Model Comput Simul 8(1):3-30

Ministry of Land, Infrastructure and Transport (MLIT) (2007) Countermeasure guidebook of methane gas for facility development and management (in Japanese). http://www.ktr.mlit.go.jp/ktr_content/content//00061 6915. Accessed 1 Nov 2018

Park J-O, Tsuru T, Kodaira S, Cummins PR, Kaneda Y (2002) Splay fault branching along the Nankai subduction zone. Science 297(5584):1157-1160 
Sato H, Hirata N, Koketsu K, Okaya D, Abe S, Kobayashi R, Matsubara M et al (2005) Earthquake source fault beneath Tokyo. Science 309(5733):462464. https://doi.org/10.1126/science.1110489

Sawaki T, Kaneko N (2010) Significance of geoinformation for study on "Minami-Kanto Gas Field". Chishitsu News 667:53

Sheriff RE, Geldart LP (1995) Exploration seismology, 2nd edn. Cambridge University Press, Cambridge, p 415

Takemura S, Akatsu M, Masuda K, Kajikawa K, Yoshimoto K (2015) Long-period ground motions in a laterally inhomogeneous large sedimentary basin: observations and model simulations of long-period surface waves in the northern Kanto Basin, Japan. Earth Planets Space 67:33. https://doi. org/10.1186/s40623-015-0201-7

Takii S, Tanaka H, Aizaki M (2001) Sulfate reduction and methane production in sediments of the inner part of Tokyo Bay. J Jpn Soc Water Environ 24:35-41. https://doi.org/10.2965/jswe.24.35
Tsuji T, Matsuoka T, Kadir WGA, Hato M, Takahashi T, Sule MR et al (2014) Reservoir characterization for site selection in the Gundih CCS project, Indonesia. Energy Procedia 63:6335-6343

Tsuru T, Park J-O, Miura S, Kodaira S, Kido Y, Hayashi T (2002) Along-arc structural variation of the plate boundary at the Japan Trench margin: Implication of interplate coupling. J Geophys Res. https://doi.org/10.1029/2001 J B001664

Tsuru T, Park J-O, No T, Kido Y, Nakahigashi K (2018) Visualization of attenuation structure and faults in incoming oceanic crust of the Nankai Trough using seismic attenuation profiling. Earth Planets Space 70:31. https://doi. org/10.1186/s40623-018-0803-y

Usami T (1996) Materials for comprehensive list of destructive earthquake in Japan [Revised and enlarged edition]. Univ. of Tokyo Press, Tokyo, pp 143-153 (in Japanease)

Yilmaz O, Doherty S (1987) Seismic data processing, vol 2. SEG, Tulsa

\section{Submit your manuscript to a SpringerOpen ${ }^{\circ}$ journal and benefit from:}

- Convenient online submission

- Rigorous peer review

- Open access: articles freely available online

- High visibility within the field

- Retaining the copyright to your article

Submit your next manuscript at $\boldsymbol{\nabla}$ springeropen.com 